\title{
Developing a Disposition to Teaching Design and Technology: A Case Study
}

\author{
R. Hansen \& D. Davies
}

\section{Introduction}

Literature in the field of technological education has attempted, in recent years, to define technology and technological education (e.g., Dyrenfurth \& Mihalevich, 1987; Layton, 1993; Ortega, 1962; Staudenmaier, 1985; Wiens, 1988). These definitions emerge, typically, from analyses of what philosophers, sociologists, historians, and educators have written about the subject (Hansen \& Froelich, 1994). Reference to what technologists actually do in their work (Rophol, 1991) has also contributed to definition material but to a lesser extent. Missing from the mix of material for a definition is an analysis of what technology instructors do in their classrooms. The following case study provides readers and the emerging literature in technological education with a different viewpoint of technology which is powerful and compelling. The Martin Rivers (a pseudonym) case challenges our understanding of what constitutes effective teaching and learning. It explores the connection between technology and the act of learning. What are the human problem solving instincts and emotions associated with learning something from experience in the technological world? Intentionally, the case also highlights a difficulty which faces technology teachers. That difficulty is the assimilation into several potentially alien cultures made by these teachers. Firstly, there is the culture of the school with its complex hierarchy of relationships and meanings concealed by educational jargon. Secondly, and perhaps more crucially for the technology teacher, is the culture of the subject itself: a new field of study in curriculum terms; fighting for recognition and academic respectability (Goodson, 1994); blurred at the edges by its relationship with design, science, art and mathematics. It is unsurprising that new teachers take time to orient themselves within this new world. How can they be helped to achieve successful enculturation?

Technology is defined by Ortega y Gassett (1962) as the extra-natural program that is man [sic] himself. What Gassett described in his essay "Man the Technician" is a simple but also obscure idea. Human beings are programmed, Gassett would argue, to meet their needs, the most prevalent of which is to use natural and manufactured resources to solve problems. Martin Rivers'

Ron Hansen is a Professor in the Faculty of Education at the University of Western Ontario, Ontario, Canada. D. Davies is a Lecturer at Goldsmiths, University of London, Primary Science Centre, New Cross, England. 
experience is relevant to understanding technology and also science, especially the contextualization of scientific concepts through design and technological activity. His schooling as well as his early career development in teaching underscores the creative problem solving dimension of technology teaching and learning. Martin proves it is possible to help students understand the multifaceted nature of technology through imaginative projects in schools. His lifestory traces how he became a teacher and acquired the orientation to learning that characterizes his teaching. In short, the character and substance of his disposition to the profession and to learning is featured.

In life-story research (Cole, 1991), the conversation between the investigator and the interviewee is usually dominated by the participant who is asked to freely recall and reflect on life experiences. The researcher, Cole asserts, maintains a passive role, merely probing these recollections and reflections. The purity of such accounts can range from strictly autobiographical to what Connelly and Clandinin (1990) call "collaborative stories." "And in our story telling, the stories of our participants merged with our own to create new stories, ones that we have labeled 'collaborative stories'." (p. 12).

This manuscript takes as its focus the process of reflective career autobiography as a means of making sense of the culture shifts we all have to undertake in education. It makes use of the personal writing of a case-study subject who was selected because, although his career has been set entirely within a United Kingdom context and is in many ways atypical, he has articulated some of the difficulties in adjustment which many technology teachers would acknowledge to be universal. He has analyzed "critical incidents" (Tripp, 1993) which have influenced his career path, and has developed an awareness of his disposition, both towards technology teaching and towards the nature of the subject itself. The manuscript analyzes the stages of this autobiographical process and invites other technology educators to engage in similar reflection upon their own enculturation.

The purpose of case study research is to create insights and understanding rather than to generalize to a larger population. The purpose of this particular case study is to better understand how one teacher, who chose to experiment with his teaching and learning activities, came to grips with the complex territory between his instincts and tendencies and the norms/values which characterize what is thought, within the profession, to constitute effective teaching. The technology teacher perspective into the nature of technology, interestingly, is unique and can take different forms as the case which follows conveys.

\section{The Importance and Place of Creative Thinking: The Martin Rivers Case}

I am neither a designer nor a secondary school technology teacher, yet I have experienced some of the socialization problems facing new teachers entering the 'alien culture' of the school staffroom. In my case it was as a scientist making the transition between the dry academia of a traditional undergraduate physics course, and the complex social context of an inner city primary school. Although it was a shock, in some ways it was a little like 
'coming home,' and recapturing a lost part of myself. To explain this statement I need to briefly revisit some childhood learning experiences.

As a child, I was an obsessive designer-maker. In addition to the traditional construction toys, I consumed vast quantities of cardboard and sticky tape in grand projects to construct whole model towns, suits of armour and life-size robots. This would fall under the heading of 'junk-modeling,' or more recently 'modeling with reclaimed materials' in contemporary primary practice, but I had comparatively few opportunities to exercise my making skills at school. One notable exception was the teacher who, in 1968, involved my class in making paper mache electric guitars and drum kits, in order to mime along to the Beatles' recently issued Sergeant Peppers album.

One can sense that at an early stage in Martin's life he yearned for immediate and real experience with any materials he could find. His mind was alive with scenarios to be explored and ideas to be put into practice. He was already establishing values with respect to the practical or manufactured world, presumably stimulated by events around him as well as by his bountiful imagination. However, these tendencies were not often nurtured at school. The exception was a memorable project conceived by one of his teachers. What did this teacher do and know that triggered such enthusiasm in his/her students? What was Martin learning in this instance? What goal did the teacher have in mind when he/she designed the learning exercise?

I received a carpentry set for my seventh birthday, and proceeded to build a two storey tree-house with electric lighting, and a helicopter in the back garden using a rotary clothes-line. Like most pre-pubescent boys, I flirted briefly with model aeroplane kits, but never possessed the patience and attention to detail required for carefully painting each part before assembly. Making other people's designs bored me, but drawing elaborately annotated (and completely impractical) schemes for underwater cities and bizarre factories fascinated me.

At my selective state grammar school, an outlet was provided for a limited form of artistic expression in the context of traditional fine art classes. The situation with regard to designing and making was, however, very different. The 'craft workshop' in which our woodwork and metalwork lessons took place was a small prefabricated hut at the far end of the playground, a situation indicative of its low status within the academic hierarchy of the school. No mention was ever made of the words 'design' or 'technology' and it was clear that, unless we were to take the 'technical drawing' ' $O$ ' Level, our brief and occasional visits to the craft workshop would soon cease. Instead I was channeled along traditional academic subject routes, with an emphasis on the sciences; regarded as having the highest status of all. I did manage to retain my art, taking it to 'O' level, but without great success.

It appears that Martin's desire and aptitude for "making and doing" was not being recognized or channeled in his schooling. If anything he was being asked to defer his apparently natural and deep tendencies to "design and make" activities while in school. Mention of the "academic route" is a familiar refrain in his writing. 
I transferred to a sixth-form college at age 16, determined to take an 'A' level in design, alongside my maths, physics and chemistry. However, even here the design was looked down upon, seen as a dubious university entry qualification and a distraction from my real work. Reluctantly, I agreed to replace the design with further maths, turning myself into a narrowly focused physical scientist. I soon discovered, however, that I could use some of my creativity and three-dimensional mental modeling in the physics course, and became excited about the increasingly beautiful pictures of atomic structure to which we were being introduced. This realization of the intuitive and creative aspects within scientific thinking determined me to pursue physics at a higher level.

The creative and intuitive aspects of scientific thinking, (presumably inspired by the colorful illustrations used in print materials describing how something works in three-dimensional space) were obviously very much a part of Martin's make-up albeit in the abstract world of physics. Little did he know that such abstractions and the mathematics required to understand them would dominate his energies in higher education.

The university physics department in which I took my first degree has an international reputation, but not for the quality of its undergraduate teaching. The lectures were dry and didactic, delivered by academics who clearly resented this interruption to their research, in large, dimly lit lecture theatres. For the bleary-eyed undergraduates who squinted to read the spidery hieroglyphics covering several blackboards, it shattered many illusions. Interaction was minimal even in tutorial groups, during which our professor would insist upon deriving every equation used from first principles, hence failing to cover the set problems and losing everyone in the process. As I became bogged down in the mathematical minutiae of relativistic quantum mechanics, the beautiful models in my head began to become blurred and hazy, and I finished three years of university study determined never to read another physics textbook.

The one highlight in an otherwise disillusioning experience was a project at the end of our first year intended to introduce us to the design and manufacture of experimental apparatus. We were given a short metalwork course in the departmental technicians' workshop, and the brief to design a sun-sensor to enable a satellite to orientate itself in orbit. The selected design was to be built by the technicians for demonstration to succeeding years of students. My design was chosen, and I felt again the tremendous sense of satisfaction which designing had given me as a child. Again, fleetingly in my final year I had the opportunity of designing a wave energy collection device, sparking an enthusiasm for alternative energy sources which was to be frustrated by the lack of research funding for such 'trivial' projects.

Despite my frustration at the unimaginative approach to degree-level physics, I still felt an excitement about the ideas I had acquired at secondary school, and applied for a Post Graduate Certificate in Education (PGCE) to become a physics teacher. As a part of this course we were required to spend two weeks in a primary school, my first visit in ten years The experience was to have a profound affect on my subsequent career. I realized that the nonscientific aspects of my nature, which had been gradually suppressed by my 
convergent education, could actually be rediscovered and find expression in working with young children. Restricting myself to being a 'teacher of physics' was becoming an artificial strait-jacket, and I resolved to reapply for the primary PGCE course, which I completed in 1986 before taking up a post in the Inner London Education Authority (ILEA).

Inner London primary schools in the mid-1980s were very much influenced by the informal, integrated curriculum and child-centered approach reflecting the work of developmental psychologists from the 1960s onwards. This was before the long slide back to 'traditional teaching methods' under successive Secretaries of State for Education and the accompanying successive waves of legislation. I was appointed to work in a mixed-age, open-plan infant area, team-teaching sixty 4-7 year olds. The culture shock was profound. I found myself unfamiliar with the cultures of the children, and with the mind-set of my colleagues. There was little which I could recognize as a curriculum; the children each following their own interests in different 'areas' of the learning environment: construction, role-play, sand and water, reading and writing. The depth of appreciation required of child development and the ways in which different subject areas contributed to a holistic approach was frightening, and I found myself deferring to my more experienced arts-trained colleagues. My educational background seemed largely irrelevant - I did not even feel confident in teaching primary science.

Life as a professional teacher was beginning to take on more meaning for Martin. He could see an opportunity to express some of his intrinsic needs for a more imaginative and progressive curriculum in which children could experiment more freely with the materials and objects in the world around them.

Gradually I began to orientate (sic) myself and find my feet in this strange new world. In particular I became fascinated by young children's behavior when making things; the way they projected a wealth of meaning and significance into a seemingly simple cardboard construction. I marveled at their ad-hoc and ingenious methods for joining materials, and the painstaking care they took in choosing the right shape of box or scrap of fabric for their needs. The empathy children showed for toys or story characters could find expression in designing for imaginary needs, and the emerging subject area of primary design and technology in the late 1980s had a vibrancy that excited me, in the same way that physics once had.

A major career opportunity came my way with the legitimacy given to design and technology in the National Curriculum for England and Wales in 1989. Suddenly there was a huge demand from primary teachers for inservice training, and I found myself regularly running courses at my local teachers' centre. In many ways design and technology was less familiar to many primary teachers than science, and despite the fact that many of them had been involving children in 'design and make' activities for years, they felt intimidated by the concept of a 'design process,' and the negative associations of the word 'technology.' The National Curriculum for Design and Technology was at this stage heavily influenced by the design education lobby, in particular the Design Council, a government funded design-promotion body, which had published the 
report 'Design and Primary Education' in 1987. Through this report, and the subsequent 'Signs of Design' series, the policy of the Design Council education section was to highlight the design activities already taking place across the primary curriculum, and encourage teachers to recognize and build on them. This approach very much appealed to me, by then a fully paid up 'integrationist' in primary curriculum terms, and I took up a post as Education Officer at The Design Council in 1990.

The design activity that appealed to Martin may represent a more significant development than he realizes. Are elementary school teachers unique in their preference for "design and make" activities? How widespread is this approach to learning? Their willingness to explore topics of interest and appeal to young children would seem to be more needs-based than subject-based. More important, is it an approach to learning which complements rather than complicates children's instincts and desires to learn? If so, are there any implications for the technology teacher who practices a similar pedagogy at the secondary school level? The "design and make" mindset is certainly fresh in Martin's mind and foremost in his career and personal development.

Lacking any formal design background, and with only four years primary classroom experience behind me, I encountered once again the profound 'fish out of water' sensation which had greeted my entry to the teaching profession. My learning curve was steep, visiting many professional design consultancies and dozens of schools across the South of England in the search for designrelated classroom projects for publication or exhibition. I brought with me an aptitude for quickly assimilating information - borne of many mystifying physics lectures - and an instinctive feeling for quality in primary children's designing and making. It was a privileged position to be in, and gave me many ideas for when I eventually returned to the classroom. For return I did, for a variety of reasons. The climate of opinion with regard to primary design and technology was shifting - the vocational/engineering lobby was beginning to make loud noises about the lack of rigour in contemporary classroom practice - and the design educators were in retreat. The National Curriculum Orders were subsequently changed, emphasizing 'structures and mechanisms,' and the Design Council's influence waned considerably. Soon my post was to be abolished, but fortunately I had seen the writing on the wall and managed to secure a position as Science and Technology co-ordinator in a local primary school.

One can sense the imminence of a turning point in Martin's teaching career. The need for a more flexible way to learn and help others learn is crystallizing for him. His effort to alter the didactic instructional approach so dominant in his own schooling is a challenge from which he did not want to back away.

In the period I had spent away from teaching, much had changed. The National Curriculum, with its detailed requirements for three core and six foundation subjects, was now fully in place, and given extra coercive power by the structure of testing at ages 7 and 11. I found that the flexibility I had previously enjoyed in structuring my own design topics was considerably reduced, and was forced to consider how to keep within strict time allowances for each subject area. This did not prevent me from pursuing some of the lines of 
interest I had developed at the Design Council, such as the use of professional designers working in the classroom with children. I undertook a project with the Royal Opera House, involving children in writing, designing and producing their own opera over a period of a school term. The children worked closely with a professional theatre set and costume designer, resulting in a spectacular visual extravaganza which I was able to write up as a Masters dissertation.

The project was not without its costs, both in terms of my stress and the gaps in coverage of the curriculum. I determined to concentrate once more on science, the 'core' subject which I had neglected for so long. As I took my coordinator's job more seriously I found myself once more becoming excited by scientific concepts, and particular by the constructivist approach of building upon children's existing ideas. I began to explore ways in which scientific learning and design capability could be linked more closely in the classroom, discovering that children frequently failed to transfer knowledge and skills between one context and another. In a sense I had come full circle, trying to integrate the two essential parts of my make-up. It is a struggle in which I am still actively engaged!

What are the essential parts of Martin's disposition to learning? This question is central to understanding how learning and technology are interrelated. It helps explicate the relation between technology and one's instinct to learn. In this instance Martin's desire and capacity to learn through experience (an essential feature of learning in the practical world), while dampened and stifled in his formal schooling, is very much a constant in his "informal" learning. The acquisition of new experiences and the complementary activity of learning associated with those experiences are delicately and usefully balanced. Knowledge is not an end in itself for Martin. His disposition to learning is existential - it is fresh and on-going. His disposition to learning uses divergent as well convergent thought processes to comprehend, inductive as well as deductive learning methods to reflect/contemplate.

How widespread is such eclectic learning? More widespread than the literature on "learning" would have us believe? The very fact that Martin's story is one of unease with the formal school system in which he and many like him endure, is telling. To what extent does every young learner possess the instinct and tools to learn that Martin exhibits? To what extent are those tendencies extended or denied within the formal school curriculum?

Once again my career was about to enter a period of flux. The opportunity to become involved in the initial training of student teachers arose, and I applied for a post at a reputable University, lecturing in primary science education. Suddenly I was once again a 'specialist scientist' with only one area of the curriculum upon which to focus, and I had to readjust to a very different academic world from the one I had experienced as an undergraduate. This university is dedicated to the arts and education, and I became one of very few science-related staff in the entire institution. My fascination with the links between primary science and design became my 'research interest' as I entered the academic's publication 'rat-race,' despite being primarily a trainer of teachers. I regained a degree of autonomy in planning my own courses and 
managing my own time; midway between the rigid timetable of the primary school and the self-managed agenda of the education officer. I have decided that, at present, a scholar is what I definitely aspire to be!

Having matured and found a career in which he could extend his capabilities and express his views, Martin had reached a state of selfactualization - a stage of achievement not often documented in the professional education literature. His final reflections serve as an epilogue to his life-story and as a lesson to others who recognize themselves and/or their experiences in this documentation.

My (to date) varied career in education has taught me that it is often the institutional culture of a workplace which requires time for adjustment, possibly to a greater degree than the actual daily demands of the job. Another recurring theme is that skills which appear at first glance to be redundant in a particular context have a way of re-surfacing later, often in an unexpected way. No experience or learning is ever wasted, all that is required is the mental flexibility to re-work it for a fresh set of circumstances. In the case of science and design, they seem almost to belong to two separate cultures until we perceive that the mental processes involved have distinct parallels, demonstrated many times in my career from childhood to the present moment. I appear to be groping towards a position which sees the two areas as distinct yet inextricably linked, equal in partnership for the needs of society and the education of children.

\section{Discussion}

Martin's development as a teacher and his socialization into the profession reminds teacher educators of an important premise upon which teacher development hinges. Teachers can only come to understand what it means for a student to be educated when they think first of themselves as learners and reflect on the nature and course of their own education (Hansen, 1998). Martin Rivers has done this. The tensions which characterized his own schooling and his career as a teacher gave him the chance to confirm the beliefs and values associated with learning which he cherishes and which are explicated in this case study. Is this development the substance of one's progress and success as a teacher? His development as a learner and as a professional educator was quite a turbulent one.

Philip Jackson's (1968) classic book "Life in Classrooms" testifies to the many aspects of school and classroom life which become an integral part of each teachers' experience base but which are seldom analyzed. Jackson's rich descriptions of what really happens in schools demonstrate how one's values and competencies can match with or diverge from the predominant ideology about learning in a school setting and what is thought to be good teaching. The implications for teacher development and socialization are considerable. A teacher's development and subsequent socialization involve a reconciliation between the informal and formal cultures of the classroom and school. That reconciliation process is critical to understand for all who choose to practice in the profession.

Martin's case, in addition to describing an awkward but successful adjustment within the profession, uncovers an important element of personal 
development for teachers. This aspiring professional made adjustments to accommodate the predominant norms and values held by a system or school within a system. His work as a teacher and his willingness to be a reflective practitioner challenge those norms and set a new standard for teachers who aspire to practice effectively and critically in the profession. Had the system itself been more receptive to Martin's experiences and tendencies his adjustment process might have been an easier one, but would it have been less problematic? Teachers who prepare for the profession today are asked to embrace a rather narrow conception of how students learn which is based on the wisdom of educational psychology scholars. Their [teacher candidates] preparation and the learning of their students is seldom based on a comprehensive analysis of individual experiences and needs, teacher or student. The human development and learning goals characterized in Martin's autobiography are not articulated much less pursued. Yet a more relevant and meaningful curriculum, the most widely discussed and analyzed problem in the education literature today (in technology as well as other subject areas), may depend on the voices and critical analysis skills of reflective teachers like Martin.

The Martin Rivers case demonstrates, above all else, that technology and learning can be thought of as synonymous activities. Martin had an appetite for new experiences and knowledge which was as natural and unencumbered as eating and sleeping. Its roots were instinctual for him. Designing and making, for Martin, was and is a way of learning and knowing. His desire (the extranatural program that Ortega y Gassett describes) to explore and alter the natural and manufactured world (the world of technology) is unending. In short, Martin's instinct to learn is an instinct to "experience." That "experiencing" is a technological phenomenon.

\section{References}

Cole, A. L. (1991). Interviewing for life history: A process of ongoing negotiation. In Ivor F. Goodson and J, Marshall Mangan (eds.), Qualitative educational research studies: Methodologies in transition, Vol. 1, (pp. 185209). Research Unit on Classroom Learning and Computer Use in Schools, Occasional Papers, Faculty of Education, The University of Western Ontario, Canada.

Connelly, F. M., \& Clandinin, D. J. (1990). Stories of experience and narrative inquiry. Educational Researcher, 19, 2-14.

Dyrenfurth, M. J., \& Mihalevich, J.R. (1987). Technological literacy: More than computer literacy! (Paper presented at the National School Boards Association Conference, Dallas, Texas). ERIC Publication No. ED305901.

Goodson, I. (1994). Studying curriculum. Milton Keyes: Open University Press.

Hansen, R. E. (1998). The socialization of technology teachers: Two unique cases. Journal of Industrial Teacher Education, 35(2), 29-40.

Hansen, R., \& Froelich, M. (1994). Defining technology and technological education: A crisis, or cause for celebration? International Journal of Technology and Design Education, 4, 179-207. 
Jackson, P. W. (1968). Life in classrooms. New York: Holt, Rinehart, and Winston.

Layton, D. (1993). Technology's challenge to science education: Cathedral, quarry, or company store? Open University Press, Buckingham.

Ortega y Gassett, (1962). History as a system and other essays toward a philosophy of history [originally published under the title Toward a Philosophy of History]. New York, NY: W. W. Norton \& Company.

Rophol, G. (1991). Deficiencies in engineering education. In Paul T. Durbin (ed.), Critical perspectives on non-academic science and engineering, (pp. 278-295). Bethlehem, PA: Lehigh University Press.

Staudenmaier, J. (1985). Technology's storytellers: Reweaving the human fabric. Cambridge, MA: The MIT Press.

Tripp, D. (1993). Critical incidents in teaching, London: Routledge.

Wiens, A. E. (1988, November). Technology education as part of undergraduate liberal education. In Daniel L. Householder (ed.), Proceedings of the 75th Mississippi Valley Industrial Teacher Education Conference: Industrial Teacher Education in Transition, (pp. 191-218). St. Louis, MO. 